\title{
INTERSTÍCIOS DA (IN)TRADUZIBILIDADE NO CONTO O "OVO E A GALINHA" DE CLARICE LISPECTOR
}

\author{
(UN)TRANSLATABLE INTERSTICES IN CLARICE LISPECTOR'S OVO E A \\ GALINHA
INTERSTICIOS DE (IN)TRADUCIBILIDAD EN EL CUENTO “O OVO E A GALINHA" DE CLARICE LISPECTOR

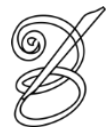 \\ Jhonny Alexander CALLE OROZCO ${ }^{1}$ \\ Mestrando em História \\ Grupo de Pesquisa em Tradutologia \\ Universidad de Antioquia \\ Medellin, Colômbia \\ jaco142@hotmail.com
}

Resumo: Este artigo parte de uma análise detalhada do conto "O Ovo e a Galinha", escrito por Clarice Lispector e lido no Congresso Mundial de Bruxaria, realizado na Colômbia, em 1975, e na qual integra-se as múltiplas dimensões semânticas do trabalho com as próprias interpretações e atitudes da autora quando o escreveu. Depois, com base no conceito de intraduzibilidade, além de abordar as possíveis traduções que foram (e podem ser) feitas do texto, procuro mostrar como todas estas emergem do interstício que se forma entre o linde da tradução e o começo de uma forma de recreação.

Palavras-chave: intraduzibilidade, Clarice Lispector, tradutologia

Abstract: This article begins with a keen analysis of Clarice Lispector's story "O Ovo e a Galinha", shared during a Witchcraft World Congress, held in Colombia, in 1975. This analysis integrates the multiple semantic dimensions presented thereto with the author's own attitudes and interpretations when she wrote it. Then, building on the concept of untranslatability, I seek not only to highlight all possible translations of the text, but also to surmise how all those translations emerged from the interstice between the translation boundaries and the beginning of a form of recreation.

Keywords: untranslatability, Clarice Lispector, translation studies

Resumen: El presente artículo parte de un análisis detallado del cuento "O ovo e a galinha", escrito por Clarice Lispector y leído en el Congreso Mundial de Brujería, realizado en Colombia, en 1975, y en el que se integran las múltiples dimensiones semánticas de la obra con las propias interpretaciones y actitudes de la autora al momento de escribirlo. Tras ello, partiendo del concepto de intraducibilidad, más allá de señalar las posibles traducciones que pueden hacerse y que se han hecho del texto, se busca entrever cómo todas éstas se gestan entre el linde de la traducción y el comienzo de una forma de recreación.

Palabras clave: intraducibilidad, Clarice Lispector, traductología 


\title{
1. À guisa de introdução
}

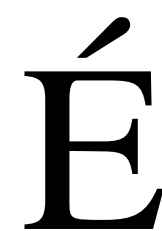

desnecessário ressaltar a importância repentina e consequente das obras de Clarice Lispector no desenvolvimento e na consolidação da literatura latino-americana. A própria presença do seu nome em muitos círculos contemporâneos de análise literária ecoa na magnificência dos seus escritos. Foi-lhe dedicada pelo menos uma centena de páginas à análise de sua prosa e poética e, em cada leitura das diversas interpretações que suscita, se fixa a ideia clara de que a poética lispectoriana renuncia ao "racional" e "natural" do código realista e vanguardista, porém, permitindo-se, às vezes, uma forma de pensamento "racional" e "natural". Mas ainda, seu conto "O ovo e a galinha" (1964) é, talvez, entre seu acervo literário, a produção mais mística e enigmática, resultando para si própria um texto misterioso que porta certa simbologia secreta:

\begin{abstract}
Alguém vai ler agora em espanhol um texto que eu escrevi, uma espécie de conto chamado "O ovo e a galinha", que é misterioso mesmo para mim e tem sua simbologia secreta porque, se vocês tentarem apenas raciocinar, tudo o que vai ser dito escapará ao entendimento. Se uma dúzia de ouvintes sentir o meu texto, já me darei por satisfeita. E agora por obséquio ouçam "O ovo e a galinha", que é misterioso mesmo para mim e tem uma simbologia secreta. Eu peço a vocês para não ouvirem só com o raciocínio porque, se vocês tentarem apenas raciocinar, tudo o que vai ser dito escapará ao entendimento. Se uma dúzia de ouvintes sentir o meu texto, já me darei por satisfeita. ${ }^{2}$
\end{abstract}

Lido no Congresso Mundial de Bruxaria, realizado na Colômbia, entre os dias 24 e 28 de agosto de 1975, o conto se tornou um arado fértil onde germinaram monólogos de peças de teatro $^{3}$, críticas de todo tipo (aquelas baseadas nas supostas imperfeições e ambiguidades que pressupõem a obra, (ver, por exemplo, Alvaro Linsy e Costa Lima) ${ }^{4}$ ) e até mesmo reinterpretações voltadas ao gosto banal de encontrar um sentido estrito e limitado no agitado e vago universo lispectoriano. É claro que, com relação a este último aspecto, é necessário acrescentar a vasta e complexa densidade do texto lispectoriano, porquanto seu método - se for possível chamá-lo desse jeito -, baseia-se em contradições ${ }^{5}$, repetições cheias de ritualidade, misticismo ${ }^{6}$ e associações livres que saltam aos olhos como digressões impertinentes, que validam o uso da extrema irracionalidade como veículo para sulcar as ideias disparatadas que apresenta na obra.

À extrema longitude do texto (aproximadamente quinze páginas), soma-se a brevidade de um instante: uma mulher se encontra, um dia qualquer, frente a um ovo. Um ovo que ocasiona na espectadora uma sorte de subterfúgio que dá lugar a reflexões incoerentes que partem desde sua experiência imediata de estar vendo um ovo $^{7}$, e um ovo, que em si próprio não é nada, pois meramente se transforma num símbolo, que desborda a experiência gráfica do momento, 
e se torna um curinga em cada uma das suas reflexões até o ponto de sufocá-la. É difícil acreditar que de uma unidade de significação aparentemente tão incoerente surge um desenho claro de semelhante proporções.

Além do efeito que pode causar no leitor, o caos que se forma neste espaço textual desgasta e fratura os limites dos gêneros literários, entrevera com outros tons, oscila entre a sátira e a ironia, alterando sua aderência a formas preestabelecidas do discurso. Embora seja verdade que abundam nuances filosóficos transversais à obra, os mesmos parodiam a lógica filosófica, o estruturalismo que caracteriza os textos contemporâneos, e a banalidade coloquial do método científico. Por isso, o conto é, por sua vez, o encontro fatídico entre duas formas discursivas: discurso feminino (cozinha) - discurso masculino (filosofia) ${ }^{8}$.

Pode-se compreender que este acordo entre duas formas parcialmente discordantes de pensamento e ação, e esta ruptura dos limites discursivos na obra lispectoriana, tenham produzido um efeito indesejado no leitor: desconhecimento e incompreensão. Desconhecimento de uma forma narrativa plana e menos ambígua, que remete a espaços e figuras concretas, bem como a incompreensão de uma forma tão particular de pensar que se reflete com exata integridade nas palavras que descrevem tal forma de pensamento. Portanto, no plano literário-filosófico e, em especial, partindo de sua própria experiência como sujeito, Lispector não explora as reflexões que se desprendem de dois objetos (o ovo e a galinha), mas tende a um revesado equilíbrio numa sequência infinita de transformações. Sua estratégia, para isto, se fundamenta no fato de perder-se nos caminhos labirínticos dos mal-entendidos e das sequências absurdas do pensamento:

O ovo é uma coisa suspensa. Nunca pousou. Quando pousa, não foi ele quem pousou. Foi uma coisa que ficou embaixo do ovo. - Olho o ovo na cozinha com atenção superficial para não quebrá-lo. (LISPECTOR, 1977: 35).

$\mathrm{Na}$ análise metafísica do conto de Clarice Lispector, que nos fornece Russotto (1996), intitulado "Encantamiento y compasión, un estudio de El huevo y la gallina", a autora expõe um panorama tripartido, no qual explicita as três metáforas de identidade das quais se vale Lispector para "apresentar uma transformação da realidade e das relações humanas [...] profunda e radical” (Russotto, 1996:168). A primeira, segundo a autora, remete-se à elevação quase sublime da galinha e do ovo à problemática filosófica do binômio substância e acidente. A segunda encanta-se pela similitude metafórica entre galinha e mulher e, com isso, desconstrói o discurso patriarcal, reconhecendo a mulher no plano social e cultural, mitificando e idealizando a maternidade e a feminilidade. Mais ainda, a autora considera um 
terceiro quadro metafórico nesta complexa obra: a relação táctica entre obra e produtor (bem se convalida esta afirmação na maravilhosa metáfora dos agentes:

\begin{abstract}
Nós, agentes disfarçados e distribuídos pelas funções menos reveladoras, nós às vezes nos reconhecemos. A um certo modo de olhar, a um jeito de dar a mão, nós nos reconhecemos e a isto chamamos de amor. E então não é necessário o disfarce: embora não se fale, também não se mente, embora não se diga a verdade, também não é mais necessário dissimular. (LISPECTOR, 1997: 39).
\end{abstract}

Decididamente, encontramos na filosofia lispectoriana indícios de um feminismo literário e um olhar externo do seu próprio papel como agente. Partindo disto, poderíamos, modestamente, considerar o construto, como afirmara Russotto, de um programa capaz de encaixar, sucintamente, pelo menos, "uma ética e uma estética estritamente clariceanas" (Russoto, 1996:169). Além disso, tendo diante de nós o ovo, em sua forma textual, um símbolo linguístico que transgride sua própria representação, germina abúlica a metáfora na qual deve se deter todo tradutor que empreende a tarefa de mover a substância do seu contentor a um outro menos ajustado e mais impróprio. As possibilidades e as interpretações a que nos leva um texto destas proporções traslada o problema de tradução ao sujeito que 24 traduz: (o que sei, o que entendo do texto que traduzo? Quer dizer, eu, em tanto que agente que mira o texto, que posso saber do texto mesmo?). Questionamos a legitimidade do texto traduzido, especificamente o conto "O ovo e a galinha", ao reconhecer que toda tradução leva consigo, se não for perdas, mutilações e transmutações do texto original. Isto nos leva, mais uma vez, a falar na canônica subversão do texto traduzido ao original; porém, indo mais além, nosso objetivo é, novamente, avivar o debate sobre o que é traduzível e o que não é traduzível, visando, ao mesmo tempo, vislumbrar o linde da tradução e o começo de uma forma vaporosa de recreação.

\title{
2. Considerações práticas sobre a intraduzibilidade
}

Algumas palavras devem ser ditas sobre a inquestionável canonicidade de um termo que tem sido muito debatido nas recentes aproximações à consolidação da história e da teoria da tradução: a intraduzibilidade.

Experiência das obras e do ser-obra, das línguas e do ser-língua. Experiência, ao mesmo tempo, dela mesma, da sua essência. Em outras palavras, no ato de traduzir está presente um certo saber, um saber sui generis. (BERMAN, 2012: 23).

Quando Berman (2012) propõe sua definição de traductologia, como experiência, compreende, por sua vez, o "valor" do intraduzível, contrário ao traduzível, como altamente racionável. Ou seja, em suas próprias palavras, a intraduzibilidade do texto é uma forma de 
autoafirmação do mesmo, no que, de uma forma ou de outra, se conserva intacta e inalterável sua própria essência:

De fato, em todos os âmbitos da escrita, a intraduzibilidade é tendencialmente vivida como um valor. [...]Todo escrito quer, no entanto, preservar em si uma parte de intraduzível. (BERMAN, 2012:56).

Deste modo, Berman se permite afirmar que, se a tradução procura ligar indissociavelmente símbolo linguístico e sentido, especificamente no campo da poesia, só se pode chamar de traição, mesmo quando esta mesma traição resulta necessária para a preservação e continuidade do texto, além, inclusive, da comunicação:

Se este quer unir em si a letra e o sentido indissociavelmente, a tradução só pode ser traição, mesmo se essa traição é necessária à própria existência dos intercâmbios e da comunicação. (BERMAN, 2012:56).

Retomando o tema da intraduzibilidade, Hurtado (2001:639) indica que, desde o século XV, até os nossos dias, os estudos de tradução que tem como objetivo delimitar e compreender integralmente o conceito de intraduzibilidade se tem limitado a entender a assimetria entre o texto traduzido e o texto original, bem como as perdas que provocam toda tradução. É possível presumir, portanto, que a incapacidade da tradução de integrar, sem perda, sentido e letra radica na distância que separa línguas e culturas. Soma-se a este debate, por um lado, a crença de que o tradutor nunca conseguirá reescrever o texto com a mesma exatidão com a qual o autor original do texto reescreveria o mesmo texto na cultura de chegada e, por outro lado, também se considera impossível a tradução de certos textos, pois esta última se entretece, incontestavelmente, no código linguístico da cultura de chegada, tornando-se, desse jeito, palavras forâneas, em terrenos desconhecidos. Em outros termos, a alteridade cultural não é puramente transmissível. Portanto, para que fosse desse modo, a comunicação teria que se realizar nos mesmos códigos linguístico-culturais que compõem o texto original, (não sendo esse o objetivo da tradução, que permite a comunicação entre o texto original e o texto traduzido).

Para Hurtado (2001:640), os defensores da intraduzibilidade criticam a tradução por sua "incapacidade de adotar a identidade do original", sendo esta, segundo os defensores da tradução, justamente sua riqueza e razão de ser. É precisamente porque existe um texto estrangeiro e desconhecido no código linguístico de uma cultura particular, que a tradução é viável, relevante e especialmente necessária. Contudo, neste panorama parece desnecessário perguntar-se pela traduzibilidade do texto literário, quando é precisamente a tradução do texto 
literário o que nos tem permitido analisar outras questões, como, paradoxalmente, a intraduzibilidade do mesmo.

Não obstante, adentrando-nos mais na inquestionável presença da ideia de textos que não podem ser parciais ou totalmente traduzidos, parece ser que devemos retomar o inquebrantável anelo e nostalgia que se adota nas antípodas dos teóricos da tradução, por uma Língua Perfeita, parâmetro para todos os outros idiomas, que permitiria uma comunicação total entre as línguas. Desse modo, nas reflexões teóricas, por exemplo de Umberto Eco, no seu livro La búsqueda de la lengua perfecta (1994), evidencia-se a relevância que este e outros teóricos têm confiado à língua adâmica originária, prévia à confusão das línguas. Segunda ele: "el sueño de una Lengua Perfecta ha durado mucho y todavía no está completamente muerto" (Eco, U. 1994:449). No Task of the Translator (2011), de Walter Benjamin, o autor concorda que não são inteiramente reproduzíveis os significados da língua de partida na língua de chegada, pois é preciso e válido entregar-se ao sentimento de que as línguas convergem, todas, em uníssono, numa única língua que transcende o vazio insuperável que se gera em duas línguas tomadas por separado:

\begin{abstract}
Nesta língua [pura], que já não quer dizer nada e nada mais expressa, e que, inversamente, é, enquanto palavra inexpressiva e criadora, o que se quis dizer em todas as línguas, reúne-se finalmente toda a comunicação, todo o sentido e toda a intuição numa região, na qual eles estão destinados a extinguir-se. E precisamente nela se confirma a liberdade da tradução como uma nova e mais elevada prerrogativa. Ela não deve a sua existência ao sentido da comunicação, do qual a tarefa da fidelidade consiste precisamente em emancipar-se. A liberdade comprovase antes, submetendo à língua pura a sua própria (aceitando a atualização da língua pura na sua própria). A tarefa do tradutor consiste em redimir na sua própria língua, esta língua pura que está desterrada em terra alheia, descativá-la da obra em que está presa, dando-lhe forma poética. (BENJAMIN, 2011:11).
\end{abstract}

Entre muitos dos pensadores sobre a intraduzibilidade de uma língua, como os anteriores mencionados, há muitos outros que ainda desejam encontrar essa língua originária. E, longe de aceitar a intraduzibilidade como uma incapacidade de alterar o status quo de uma obra original, acreditam na possibilidade de identificar uma língua do pensamento, naturalmente em concordância com o funcionamento universal da mente humana e cujos termos e enunciados podem ser expressos em uma língua formalizada. Quer dizer, em outras palavras, que é necessário abandonar o terreno da pluralidade linguística e tornar a uma língua inicial, desde a qual é possível encontrar os significados originários e, portanto, abandonar todo intento de contrapor sistemas linguísticos muito diferentes em dois planos culturais divergentes. 
Do ponto de vista dialético, podemos abarcar a invalidez de tal presunção utópica. A antítese de uma língua originária reside na mesma língua incapaz de reproduzir os códigos primários, quer dizer, uma capacidade de inadaptação entre a língua utópica originária e a língua expressiva e atual, na qual os significados não têm um equivalente ou possibilidade de expressão. Contudo, a tradução permitiria a supressão dessas barreiras linguísticas que se travam entre a língua utópica originária e o resto das línguas, razão pela qual a tradução mesma, se for possível, seria a síntese que reúne ambas contraposições e que legitima a capacidade de comunicação histórica e cultural.

Segundo Ricœur (2004: 23), a distância entre a língua universal aclamada e a empírica, entre o "a priori" e "a posteriori” é insuperável. Pode-se, então, admitir a distância que se tece entre a relação entre línguas e culturas. Não obstante, a tradução tem existido, como já fora mencionado e, portanto, sempre existirá. Ainda se assumimos a existência de uma Língua Viva, sua distância será, exatamente, a mesma que se gera entre os diversos membros de diferentes comunidades linguísticas.

Justamente acreditamos aqui que a questão da intraduzibilidade não emerge da distância que separa uma língua de outra língua, mas no seu funcionamento. Retomando novamente a Ricœur (2004), todo ato de comunicação se determina graças ao manejo de três unidades: palavra, frase e texto. Das palavras, os signos e o léxico, bastante abordados por Saussure, passamos à frase e sua intricada relação entre significado e referente e, a partir dessas sequências ou frases, que constituem a engrenagem textual, podemos, portanto, falar de sentido.

Retomando, pois, o tema que nos concerne e, referindo-nos novamente a Berman (2012), acreditamos que o sentido vai ligado ao uso e combinação destas três unidades textuais. No caso da obra de Lispector e sua tradução ao espanhol, algum indício de intraduzibilidade seria o mesmo que se desprende da relação entre a Língua Viva e as línguas empíricas: concentração e apreensão do sentido. Como afirmara Berman: "o sentido está condensado de maneira tão infinita que excede toda possibilidade de captação" (Berman, 2012:52). Partindo disto, é valido afirmar que o tradutor é incapaz de dilucidar o "sentido total" da obra. Mas ainda, no caso do "Ovo e a Galinha", essas unidades que o compõem são mais amplas e abstratas, criando interstícios tradutivos de maior envergadura. O ovo, na obra; símbolo da palavra e do gesto, é paradoxalmente distante do sujeito que pensa (a frase) e é ainda mais do pensamento mesmo que é pensado (o texto) e que se pensa a si próprio, entre o sujeito, que deixa de pensar, para permitir que o pensamento mesmo se vislumbre entre as trevas da 
angústia e o desconsolo. Bem é certo que estes espaços afastam o conto de uma tradução totalizadora.

\section{Clarice Lispector: uma autora (in)traduzida}

Em um breve comunicado de Lispector, em guisa de crónica poética, publicado o 12 de dezembro de 1970, e republicado em A descoberta do mundo, a autora brasileira se permite, entre os portentosos versos que compõem o texto, a escritura mais ou menos cifrada da sua própria teoria sobre tradução, ao mesmo tempo que põe em evidencia as variadas significações que podem ter as palavras e a imprecisão que lhes invade quando são extraídas do seu contexto original. A partir do termo milagre, a autora recria o pesadelo do tradutor: uma palavra que evade sua significação original ao submergir-se no contexto que lhe fornece outras novas:

Na Itália il miracolo é de pesca noturna. Mortalmente ferido pelo arpão larga no mar sua tinta roxa. Quem o pesca, desembarca antes de o sol nascer — sabendo com o rosto lívido e responsável que arrasta pelas areias o enorme peso da pesca milagrosa: il miracolo amore. Milagre é lágrima caindo na folha, treme, desliza, tomba: eis milhares de lágrimas brilhando na relva. The miracle tem duras pontas de estrela $\mathrm{e}$ muita prata farpada. Le miracle é um octógono de cristal que se pode girar lentamente na palma da mão. Ele está na mão, mas é de se olhar. Pode-se vê-lo de todos os lados, bem devagar, e de cada lado é o octógono de cristal. Até que de repente - arriscando o corpo e já toda pálida de sentido - a pessoa entende: na própria mão aberta não está um octógono, mas le miracle. A partir desse instante não se vê mais nada: tem-se. Para passar de uma palavra física ao seu significado, antes destrói-se-a em estilhaços, assim como o fogo de artifício é um objeto opaco até ser, no seu destino, um fulgor no ar e a própria morte. Na passagem de simples corpo a sentido de amor, o zangão tem o mesmo atingimento supremo: ele morre. (LISPECTOR 1992: 350)

A tradução de Lispector, por exemplo, aquela proposta por Elana Losada Soler, com sua versão para o espanhol do livro A maçã no escuro, é uma forma de reescrita que vai além de uma simples condensação de equivalências linguísticas. Para a tradutora mesma, traduzir Lispector é "tratar com algo que oferece uma dura resistência, mas ao mesmo tempo é tão frágil que pode quebrar"”, (Soler, 2013:12). O mencionado por Soler reforça nossa ideia de que traduzir Lispector não consiste em encontrar palavras novas que sejam equivalentes às promulgadas pela autora, mas reforçar as já existentes até o limite do possível.

Contudo, no complexo e intricado jogo entre criar e traduzir, o tradutor pode facilmente cruzar o umbral que torne incompreensível o texto ou, a julgar pelas nuances recriadoras das que se vale, torná-lo forâneo e afastado, até um ponto crítico, da voz lispectoriana que ressoa em cada leitura. De fato, as versões, a qualquer língua, das obras lispectorianas são reescrituras que se constroem sobre um texto que não surge desse processo de escrita 
intuitiva; mas, pelo contrário, apoiado nessa mise en corps de que tanto falara Hélène Cixous ${ }^{10}$. A intraduzibilidade dos textos de Clarice Lispector é, para a autora mesma, algo evidente. Não se reconhece, o confessa, nos "seus" textos, tecidos em terrenos alheios; pelo menos assim o afirmou, se retomamos sua entrevista com Affonso Romano de Sant'Anna e Marina Colassanti, em 1976:

CL:[...]Também não leio as traduções que fazem dos meus livros para não me irritar. MC: Elas são ruins, em geral?

C.L.: Eu nem quero saber. Mas sei que não sou eu mesma escrevendo. (LISPECTOR 1991: 5)

A impossibilidade representativa das palavras e, portanto, da tradução, transparecem de um modo mais evidente nas suas obras A hora da Estrela e Um sopro de vida. Em Um sopro de vida, por exemplo, a autora escreve: "Eu queria escrever um livro. Mas onde estão as palavras? Esgotaram-se os significados. Como surdos e mudos comunicamo-nos com as mãos" (Lispector, 1978:5). Aqui parece ser que as palavras permitem que medre essa dissociação entre palavra e significado e em $A$ hora da estrela se confirma esse pessimismo pelo que a palavra, símbolo linguístico, pode representar: "Estou absolutamente cansado de literatura; só a mudez me faz companhia. Se ainda escrevo é porque nada mais tenho a fazer no mundo enquanto espero a morte. A procura da palavra no escuro." (Lispector, 1993: 88)". Desta vez, a busca pela Língua Primária, como foi explicitado alguns parágrafos antes, é a busca lispectoriana por essa forma universal e paradoxalmente própria de contar, que parte dela, na que ela mesma se lê e que, certamente, atinge um ponto no que se desconhece. Devemos, por demais, reconhecer que é essa forma única e exclusiva de dizer o que se manifesta, pertinaz, no $O$ ovo e a galinha. O conto, portanto, precisa dessa linguagem em perpétua luta com o desconhecido:

O mal desconhecido da galinha é o ovo. - Ela não sabe se explicar: "sei que o erro está em mim mesma", ela chama de erro a sua vida, "não sei mais o que sinto", etc. (LISPECTOR, 1988: 17).

Encontramo-nos prosternados ante uma sequência de palavras simples, conhecidas por todos e que se cultivam, inclusive, no terreno da oralidade. Contudo, pouco a pouco cada uma delas vai adotando certa habilidade conceptual e consequente que separa a representação gráfica da palavra do seu significado previamente fixado (exemplo disso está na paródia do discurso filosófico: “- Será que sei do ovo? É quase certo que sei. Assim: existo, logo sei” (Lispector, 1977: 16). Esta primeira forma do texto é seguida por uma sequência de anacolutos, uma ruptura na lógica razoável do pensamento: 
O ovo não existe mais. Como a luz da estrela já morta, o ovo propriamente dito não existe mais. - Você é perfeito, ovo. Você é branco. - A você dedico o começo. A você dedico a primeira vez. Ao ovo dedico a nação chinesa. (LISPECTOR, 1977: 16)

E, desse jeito, após os exemplos anteriores, se sucedem outros de índole semelhante. O que devia fazer o tradutor diante dessas construções? Evidentemente encontraria um modo prático de reduzi-las à expressão fielmente gramatical do seu conteúdo, descompondo esses "semsentidos" ou perpetuando-os sucintamente e explicitando essas metáforas surrealistas. Com isso, claro é, o texto - conjunto de sem-sentidos - se destrói e há, curiosamente uma falta de respeito com a autora:

Ao Linotipista- [...] Agora um pedido: não me corrija. A pontuação é a respiração da frase, e minha frase respira assim. E, se você me achar esquisita, respeite também. Até eu fui obrigada a me respeitar [...] (LISPECTOR 1992: 70)

\section{Conclusão}

Em resumo, consideramos que qualquer opção referente às diversas traduções que podem se fazer e que têm sido feitas de Lispector legitima as intervenções do tradutor e deslegitima as 30 formas próprias e pessoais que a autora incluiu em cada um dos seus textos. Especificamente, a substituição dos impossíveis e absurdos gramaticais, assim como qualquer esforço por reduzir a densidade e estranheza do texto constituem uma falta de respeito com a autora mesma. É justamente essa densidade, estranheza e impossibilidade gramatical o que, num conto tão particular quanto é o "Ovo e a galinha" acrescenta-lhe sua essência e caráter enigmático.

Neste panorama, a impossibilidade da tradução do conto não procede, como muito tem sido afirmado sobre outros escritores, da translação de elementos gramaticais e sintáticos de uma língua a outra, mas da incapacidade de encontrar uma expressão, como quer que se procure, com a mesma intensidade, força e expressividade e, em alguns casos, com os mesmos absurdos e contrassensos, em uma língua diferente da língua na que foram expressos inicialmente. E porque este processo de "tradução" põe em contato o tradutor com uma língua que vai além do português: é uma língua universal, uma língua anterior à Confusão das Línguas, uma língua que, como representada nesta metáfora, invalida sua transmissão em terrenos diferentes dos seus próprios. 


\section{REFERÊNCIAS BIBLIOGRÁFICAS}

AQUINO, Cleusa. Existencialismo e visão existencial no conto "o ovo e a galinha" de Clarice Lispector. Travessia, Santa Catarina, 1980

BENJAMIN, Walter. A tarefa do tradutor. São Paulo: Editora 34, 2011

BERMAN, Antoine. A Tradução e a Letra ou Albergue do Longíquo. Florianópolis: Copiart/PGET-UFSC, 2012

BORNHEIM, Gerd. Sartre. São Paulo: Perspectiva, 1971

ECO, Umberto. La búsqueda de la lengua perfecta. Barcelona, Crítica, 1994

HURTADO, Albir. Traducción y traductología. Introducción a la traductología. Madrid: Cátedra, 2001

LIMA, L. C. O conto na modernidade brasileira. Em: O livro do seminário. São Paulo: Nestlé, 1983

LINNÉ, Vinícius. A escrita demiúrgica de Clarice Lispector. Passo Fundo (RS): Universidade de Passo Fundo, 2013

LISPECTOR, Clarice. A paixão segundo G.H. Florianópolis, Editora da UFSC, 1988

LISPECTOR, Clarice. "O ovo e a galinha". Em: A Legião Estrangeira. São Paulo: Ática, 1977, p. $81-84$

LISPECTOR, Clarice. A descoberta do mundo. 3. ed. Rio de Janeiro: Francisco Alves, 1992

LISPECTOR, Clarice. Um sopro de vida. Rio de Janeiro: Editora Nova Fronteira, 3ra edição, 1978

MEDEIROS, Vera Lucia Cardoso. O Direito ao avesso. Uma leitura de A Legião estrangeira, de Clarice Lispector.1995. Dissertação - Universidade Federal do Rio Grande do Sul

RICEUR, Paul. Sur la traduction. Paris: Bayard, 2004

RUSSOTTO, Margara. Encantamiento y compasión: un estudio de "El huevo y la Gallina". Inti: Revista de literatura hispánica, 1(43), 1996, p. 168-178

SOLER, Elana. Traducir a Clarice Lispector. "El texto ovillo y sus espejos". Espéculo, 51, 2013, p. 11-18

VAN ROSSUM-GUYON, F., ALEXANDRESCU, L., \& DÍAZ-DIOCARETZ, M. Hélène Cixous, chemins d'une écriture. Paris : Presses universitaires de Vincennes, 1990. 
${ }^{1}$ Jhonny Alexander Calle Orozco. Disponível em: http://scienti1.colciencias.gov.co:8081/cvlac/visualizador/generarCurriculoCv.do?cod_rh=0000007717

2 Cf. Marilene Felinto, "Lispector foi a congresso de bruxaria", Folha de S. Paulo, 2 ago, 1992.

${ }^{3}$ Neste respeito, permito-me salientar a grata interpretação de Angélica di Paula, na peça teatral apresentada pelo Teatro Para Alguém.

${ }^{4}$ A seus 22 anos, quando Lispector publicara seu primeiro romance Perto do coração selvagem, em 1943, o crítico Álvaro Lins considerou a obra como uma "experiência incompleta". Lins, além disso, destaca uma excessiva influência de James Joyce e Virginia Woolf no texto da autora brasileira. Este último aspecto fez com que a autora negasse rapidamente tais afirmações, argumentando que: "A [crítica] do Álvaro Lins me abateu e isso foi bom de certo modo. Escrevi para ele dizendo que não conhecia Joyce nem Virgínia Woolf nem Proust quando fiz o livro, porque o diabo do homem só faltou me chamar 'representante comercial' deles". (Em Medeiros, V. 1995:18). Luís Costa Lima, por outro lado, no seu trabalho publicado na $1^{a}$ Bienal Nestlé de Literatura: $O$ Livro do Seminário, afirma que, em Clarice Lispector: “...o espaço largo do romance permite que seus personagens muitas vezes se entreguem a monólogos filosofantes pouco rendosos..." (Lima, C. 1983:185).

${ }^{5}$ Ver, por exemplo: "mal vejo um ovo e já se torna ter visto um ovo há três milênios". (Lispector, C. 1977:35).

${ }^{6}$ Ver, por exemplo: "sei que o erro está em mim mesma", ela chama de erro a sua vida, "não sei mais o que sinto", etc. Etc., etc., etc.” é o que cacareja o dia inteiro a galinha”. (Lispector, 1977:37).

${ }^{7} \mathrm{O}$ fato de estar vendo o ovo - ponto de partida para as reflexões amorfas da escritora - é um assunto livre de propósito. Desde um ponto de vista filosófico, a partir da visão — percepção- do ovo, Lispector "penetra no caráter fundamental do amor e da vida, o serviço da existência, força latente misteriosa e cega" (Aquino, C. 1980:86). É por meio do olhar que ela se reconhece no objeto, se reconhece a si própria e, sobretudo, participa da sua própria existência. Para Sartre, justamente, o fato de olhar ao outro (o outro) tem esse caráter ontológico: "O olhar nos revela como um fato a existência do outro e a minha existência para o outro" (Sartre, J. 1971: 86). Dali parte o extenso caráter filosófico — existencialista— da narrativa.

${ }^{8}$ Nosso objetivo não é atiçar os recentes debates sobre a relação entre feminismo e as obras de Lispector. Contudo, resulta relevante salientar que é propriamente sua capacidade de escrever(se) a disjuntiva que se traça entre a recepção e a compreensão dos seus textos. A irascibilidade e calma que se interpõem no conto mostram sua portentosa habilidade para pôr em manifesto a incompreensão que provoca existir, existir de uma forma alheia, refletida na existência de outro (o ovo), que olha para ela. Esta apreciação teve o seu lugar na crítica e foi Lins o primeiro em referir-se a este ponto, ao afirmar que o caráter feminino não é capaz de dissociar a aparição da figura do autor na obra: "[...] Lins garante que os "temperamentos femininos" são incapazes de esconder a figura do autor por trás da obra de arte. Apesar da ligação passível de discussão entre a escrita e a questão do gênero, Lins aponta corretamente que Lispector, já em sua primeira obra, deixa transparecer que seu maior tema é ela mesma" (Linné, 2013:18).

${ }^{9}$ A tradução é nossa.

${ }^{10}$ A partir da sua concepção psicanalítica e cultural do feminino de Cixous —que encontra um lugar para a consciência feminina na mente criativa masculina - Françoise Defromont, no seu texto intitulado L'Epopée du corps salienta que, desde Dedans até Livre de Promethea, o discurso do corpo se faz, justamente, por une "mise em corps de la langue" e é este processo de simbolização o que encurta a distância entre o físico e o simbólico, o objeto e o signo, pois se opera sem separar o corpo da palavra. (Van Rossum-Guyon, Alexandrescu,\& DíazDiocaretz, 1990:11)

\section{RECEBIDO EM: 28 de agosto de 2015 ACEITO EM: 06 de novembro de 2015}

